\title{
Core-labelling technique (CLT): a novel combination of the ingrowth-core method and tracer technique for deep root study
}

\author{
Eusun Han* (10, Dorte Bodin Dresbøll and Kristian Thorup-Kristensen
}

\begin{abstract}
Background Ingrowth-core method is a useful tool to determine fine root growth of standing crops by inserting root-free soil in mesh-bags for certain period of time. However, the root density observed by the method does not directly explain the nutrient uptake potential of crop plants as it varies over soil depth and incubation time. We have inserted an access-tube up to $4.2 \mathrm{~m}$ of soil depth with openings directly under crop plants, through which ingrowthcores containing labelled soil with nutrient tracers were installed, called core-labelling technique (CLT). The main advantage of CLT would be its capacity to determine both root density and root activity from the same crop plants in deep soil layers. We tested the validity of the new method using a model crop species, alfalfa (Medicago sativa) against three depth-levels (1.0, 2.5 and $4.2 \mathrm{~m})$, three sampling spots with varying distance $(0-0.36,0.36-0.72 \mathrm{and}>5 \mathrm{~m}$ from core-labelled spot), two sampling times (week 4 and 8), and two plant parts (young and old leaves) under two field experiments (spring and autumn).

Results Using CLT, we were able to observe both deep root growth and root activity up to $4.2 \mathrm{~m}$ of soil depth. Tracer concentrations revealed that there was no sign of tracer-leakage to adjacent areas which is considered to be advantageous over the generic tracer-injection. Root activity increased with longer incubation period and tracer concentrations were higher in younger leaves only for anionic tracers.

Conclusions Our results indicate that CLT can lead to a comprehensive deep root study aiming at measuring both deep root growth and root activity from the same plants. Once produced and installed, the access-tubes and ingrowth-cores can be used for a long-term period, which reduces the workload and cost for the research. Therefore, CLT has a wide range of potential applications to the research involving roots in deep soil layers, which requires further confirmation by future experiments.
\end{abstract}

Keywords Deep roots, Ingrowth-core, Tracer techniques, ${ }^{15} \mathrm{~N}$, nutrient analogues, Alfalfa

${ }^{*}$ Correspondence:

Eusun Han

eusun.han@plen.ku.dk

Department of Plant and Environmental Sciences, University

of Copenhagen, Højbakkegård Allé 13, 2630 Taastrup, Denmark

\section{Background}

Despite their potential to exploit deep plant nutrient resources [35], the dynamics of nutrient uptake by deep roots is poorly understood. In fact, the majority of root investigations carried out in arable fields are limited to the topsoil (i.e. $\leq 0.3 \mathrm{~m}$ ) [22], while even annual crops can often grow roots to $2 \mathrm{~m}$ depth or deeper $[15,46]$.

In agro-forestry studies root development and uptake beyond $2 \mathrm{~m}$ of soil depth have been confirmed [8,33], while only few agronomic studies reached beyond $2 \mathrm{~m}$ original author(s) and the source, provide a link to the Creative Commons licence, and indicate if changes were made. The images or other third party material in this article are included in the article's Creative Commons licence, unless indicated otherwise in a credit line to the material. If material is not included in the article's Creative Commons licence and your intended use is not permitted by statutory regulation or exceeds the permitted use, you will need to obtain permission directly from the copyright holder. To view a copy of this licence, visit http://creativecommons.org/licenses/by/4.0/. The Creative Commons Public Domain Dedication waiver (http://creativeco mmons.org/publicdomain/zero/1.0/) applies to the data made available in this article, unless otherwise stated in a credit line to the data. 
of soil depth (e.g. [27]). One of the common reasons for the reluctance to study deep roots is the lack of suitable methods. Root methods that can be applied for root studies beyond $2 \mathrm{~m}$ of soil depth are rare and expensive to adopt. Therefore, a technical development of root methods at depth is required.

Root methods can be broadly categorized into destructive and non-destructive methods. The former includes the profile wall method [3] that has been used for determination of root distribution patterns in arable subsoil [16]. Sampling procedures such as soil core (e.g. [28, 51, 57]) and monolith sampling (e.g. [36]) have been also used for determination of rooting density, rooting depth and root architecture at various spatial scales. Such destructive methods are laborious, and number of observations is often limited.

Non-destructive approaches such as the minirhizotron technique is useful for dynamic observation of deep roots, and has been widely used in agronomic field studies in relation to nutrient dynamics of crop plants $[45$, 53]. Recently, non-invasive technique utilizing a wide range of electromagnetic radiation for root phenotyping has been proposed [56], which however, requires further investigation in field conditions.

Ingrowth-core methods are also suitable for rapid, and thereby frequent investigation of gross growth of roots [50]. The basic concept of the technique is to place a known volume of root-free soil in a mesh-bag to which, the fine roots of standing crops grow within the known time and depths. Advantages of ingrowth-core methods can be that it reduces the uncertainty of the time interval, i.e. observers can assume that the root growth occurred during the known period of time [9]. A downside of the approach is that it can be biased as roots are growing into an initially root-free environment, which would not occur in undisturbed soil. In addition, inserting the mesh bags might disturb the root growth. However, this was proven not to be significant by investigating on the root growth near to the disturbed area by the profile wall method [50].

Tracer techniques are useful tools for studying root activity-as defined "the ability of the plant root to induce changes in soil close to the root" [14], which affects plants' nutrient acquisition. This approach focuses on the plants' capacity to acquire the given nutrients by comparing the accumulated tracer contents between labelled and un-labelled plants. ${ }^{15} \mathrm{~N}$, as a stable isotope, is a well-known tracer for the study of the plant-soil interface [13], and has been used for root studies also under arable field conditions [30]. By the use of the stable isotope, $\mathrm{N}$ uptake has often been related to rooting density [55] and rooting depth [1]. Isotopes of $\mathrm{K}$ and $\mathrm{S}$ also exist, but due to high costs, nutrient analogues are often used. Among nutrient analogues $\mathrm{Li}$ has been recognized for its usefulness as an analogue to $\mathrm{K}$. One of the pioneering studies by Martin et al. [37] concluded on the validity of $\mathrm{Li}$ as a tracer after experiments in a barley and field bean intercropping set-up. Cs [59] and $\mathrm{Rb}$ [7] as monovalent cations are also known to have the same uptake mechanism as K. As an analogue to S, Se is used as it is taken up via high affinity sulphate transporters and have similar uptake pathways as $\mathrm{S}$ in plant roots [52]. In addition, radioactive tracers such as ${ }^{33} \mathrm{P}$ and ${ }^{32} \mathrm{P}$ were adopted for $\mathrm{P}$ uptake studies [12, 41], especially with mycorrhizae [42], which however, requires safer handling of the radioactivity in field conditions.

Applying tracers by injection include a risk of tracer mobility, especially in case of high rainfall after labelling [17]. This requires extra efforts to reduce the leaching risk, e.g. covering the plot surface, or to verify the movement of tracers by analyzing soil samples adjacent to the injected spots. Therefore, a secure way of labelling with a minimized risk of leaching or escaping of tracers will be helpful in tracer studies.

Incubation time of ingrowth-cores has been suggested in a wide range of periods; less than 4 weeks under actively growing annual crops (e.g. barley and potato) due to the mortality of fine roots [50], and longer than 6-9 months in boreal and temperate coniferous forests $[26,54]$. However, no field experiments have been conducted to test the optimum incubation time for determining the root growth and shoot-labelling status, and none in arable subsoils.

In tracer studies the rooting density is often determined on adjacent plants and not the plants receiving the tracer [8]. This separated approach for root uptake vs. root density investigation can potentially lead to a misleading interpretation of the data. Distribution patterns of soil nutrients and roots are highly heterogeneous, especially, in the subsoil $[22,60]$, and as a result the spots for tracer application and shoot biomass collection might not have the same conditions as the spots for root measurements.

Therefore, a feasible method that can allow us to measure the root characteristics and nutrient accumulation by the shoot of the same plants in situ is called for. The aim of this study was to develop a method for measuring root growth and activity within the same soil volume beyond $2 \mathrm{~m}$ of soil depth. For this purpose, we have combined the ingrowth-core method with tracer-labelling and developed the core-labelling technique (CLT). Alfalfa (Medicago sativa L.) was chosen as a model plant to test the CLT, as it is known for its deep-rooting capacity.

The new approach should meet the following criteria: 
- To quantify deep root growth beyond $2 \mathrm{~m}$ of soil depth;

- To allow precise location and time of tracer application;

- To allow root extraction of the labelled soil volume after the end of the experiment.

Therefore, we have constructed long sloping metal access-tubes with openings that are placed directly under plants, through which ingrowth-cores with labelled-soil are installed. We hypothesize that (i) the alfalfa roots will grow into the ingrowth-cores within a 60 days period and that tracer concentration will increase in the shoot due to the uptake; (ii) the CLT with its containment can precisely locate the labelled spot, so only the targe-plants growing directly above the labelled-spots are labelled; (iii) tracer concentration is higher after 8 weeks than 4 weeks due to the prolonged root growth period and thereby increased accessibility to the labelled soil; (iv) the CLT can demonstrate relationships between root density and root uptake activity.

\section{Materials and methods \\ Experimental site}

A field trial was established at the experimental station of the University of Copenhagen in Taastrup, Denmark $\left(55^{\circ} 40^{\prime} \mathrm{N} ; 12^{\circ} 18^{\prime} \mathrm{E}\right)$. The soil was an Agrudalf soil classified as sandy loam according to the ISSS classification. Detailed description on the soil physical and chemical condition at the study site is available in Table 1. A soil profile observation was done by national soil survey of Denmark in Tune, approximately $8 \mathrm{~km}$ away from the study site consisting of the same glacial till material. According to the survey, the soil profile consists of six horizons, viz., Ap $(0-25 \mathrm{~cm})$, Bt $(25-43 \mathrm{~cm})$, Bt $(\mathrm{g})(43-$ $66 \mathrm{~cm}), \mathrm{Cc}(\mathrm{g}) 1(66-95 \mathrm{~cm}), \mathrm{Cc}(\mathrm{g})(95-116 \mathrm{~cm})$ and $\mathrm{Ceg}$ $(>116 \mathrm{~cm})$. Weather data were collected at a weather station $0.3 \mathrm{~km}$ from the experimental site (Fig. 1). The temperature and precipitation were measured at 2 and 1.5 meters-height, respectively.

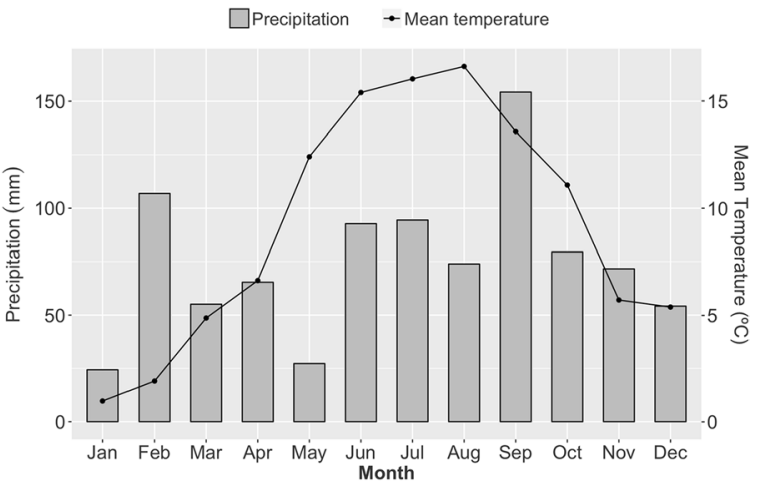

Fig. 1 Precipitation ( $\mathrm{mm}$ ) and mean temperature in 2017 at the study site

Design and installation of access-tubes and ingrowth-cores A stainless-steel access-tube (Fig. 2; left) with a total length of $5.85 \mathrm{~m}$ and an inner-diameter of $0.01 \mathrm{~m}$ was inserted using a spiral auger (Arkill Holding, Denmark) into the soil at $30^{\circ}$ from the vertical line (Fig. 3). It had $0.55 \mathrm{~m}$-long openings at three intervals at $0.85-1.40 \mathrm{~m}$, $2.6-3.15 \mathrm{~m}$ and $4.6-5.15 \mathrm{~m}$. Due to the $30^{\circ}$ angle, it created three corresponding soil depth-levels, vertically; $1.0 \mathrm{~m}(0.74-1.21 \mathrm{~m}), 2.5 \mathrm{~m}(2.25-2.73 \mathrm{~m})$ and $4.2 \mathrm{~m}(3.98-4.46 \mathrm{~m})$. The ingrowth-cores were developed as stainless-steel tube structures with openings, designed to be filled and re-packed with tracer-labelled soil and inserted into the access-tubes (Fig. 2; right). One ingrowth-core had a container of $0.55 \mathrm{~m}$-long with an inner-diameter of $0.01 \mathrm{~m}$. In the center of each ingrowthcore structure a thinner steel tube was placed, resulting in a net ingrowth-core volume of $3931 \mathrm{~cm}^{3}$. Each ingrowth-cores had 6 circular openings with a diameter of $0.06 \mathrm{~m}$ (Fig. 2; right). The openings of ingrowth-cores were designed to match those of access-tubes (Fig. 2; right) through which, the plant roots from the bulk soil can access the soil inside the ingrowth-cores. A steel rod system was developed for the insertion and retraction of three ingrowth-cores into each access-tube. The crossing bar inside the ingrowth-core was needed to provide stability upon stacking the ingrowth-cores and also to

Table 1 Physical and chemical soil characteristics at the study site

\begin{tabular}{|c|c|c|c|c|c|c|c|c|c|}
\hline Soil type & Soil depth (m) & $\mathrm{pH}$ & Clay (\%) & Silt (\%) & Fine sand (\%) & Coarse sand (\%) & $\begin{array}{l}\text { Bulk density } \\
\left(\mathrm{g} \mathrm{cm}^{-3}\right)\end{array}$ & $\mathrm{P}(\%)$ & K (\%) \\
\hline Ingrowth-core soil & & 8.1 & 12.5 & 12.4 & 45.5 & 28.9 & & 0.004 & 0.041 \\
\hline \multirow[t]{5}{*}{ Field soil } & $0-0.25$ & 7.6 & 13.0 & 15.2 & 42.3 & 27.8 & 1.56 & 0.042 & 0.110 \\
\hline & $0.25-0.75$ & 7.8 & 20.2 & 12.9 & 40.3 & 26.1 & 1.64 & 0.013 & 0.084 \\
\hline & $0.75-1.5$ & 4.5 & 19.9 & 16.3 & 37.8 & 25.9 & 1.76 & 0.006 & 0.065 \\
\hline & $1.5-3.0$ & 8.2 & 19.3 & 18.9 & 36.6 & 25.1 & 1.77 & $<0.004$ & 0.074 \\
\hline & $3.0-4.5$ & 8.1 & 19.0 & 25.9 & 33.1 & 21.7 & 1.77 & 0.004 & 0.111 \\
\hline
\end{tabular}




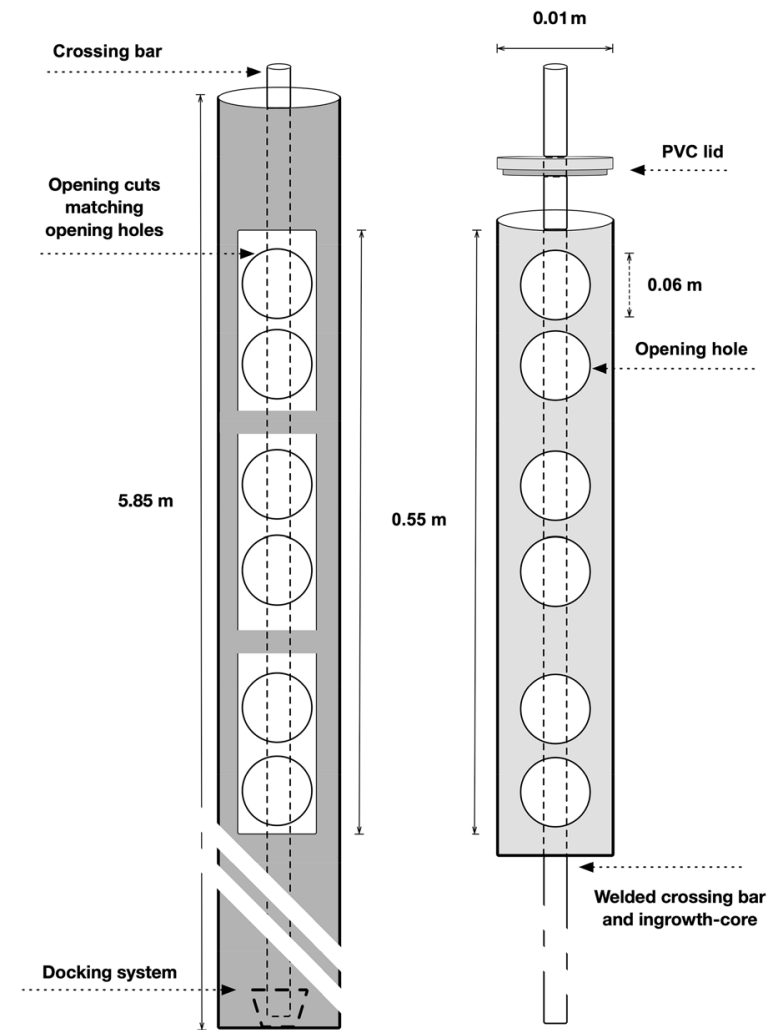

Fig. 2 Schematic diagrams of an access-tube with ingrowth-core inserted (left) and an ingrowth-core (right)

regulate the distance between them (see Fig. 2). At the bottom of the access-tube, a cylinder-shaped dockingsystem was installed as a guiding system for the placement of the ingrowth-cores into the access-tubes (Fig. 2; left). The top end of the two lower cores had a corresponding structure, so that the ingrowth-cores could be locked on top of each other. The reason for having the pre-installed semi-permanent access-tubes was to promote simpler and less laborious insertion/extraction of ingrowth-cores for long-term field trials, which otherwise require soil-drilling each time.

\section{Experimental design}

Alfalfa (M. sativa L. 'Creno') was sown on Sep 9, 2015. The seeding density was $2.5 \mathrm{~g} \mathrm{~m}^{-2}$. The crop was mowed three times per season. No fertilizer was applied during its growth. Two experiments were performed in 2017; one in spring (4 May-4 July) and the other in autumn (31 Aug-2 Nov). Access-tubes were inserted at the plot heads of six alfalfa plots $(1.5 \mathrm{~m} \times 10 \mathrm{~m})$ leading to six replicates. In the spring experiment, due to a soil collapse in one access-tube, the replicates were reduced to five.
Experimental procedure

Core-labelling

${ }^{15} \mathrm{~N}, \mathrm{Li}, \mathrm{Cs}, \mathrm{Rb}$ and Se were used as nutrient tracers. They were prepared from ${ }^{15} \mathrm{NH}_{4} \mathrm{Cl}, \mathrm{Li}_{2} \mathrm{CO}_{3}, \mathrm{Cs}_{2} \mathrm{CO}_{3}, \mathrm{Na}_{2} \mathrm{SeO}_{4}$ and $\mathrm{Rb}_{2} \mathrm{CO}_{3}$ with the amount of $275.24 \mathrm{mg}, 210.78 \mathrm{mg}$, $728.26 \mathrm{mg}, 0.474 \mathrm{mg}, 535.02 \mathrm{mg}$ per ingrowth-core, respectively. Except for ${ }^{15} \mathrm{~N}$, the assumed enrichment levels were derived from Hoekstra et al. [17]. The tracers were prepared in solution form and mixed with a subsoil medium. While re-packing the labelled soil in the spring, a high soil strength was created to avoid soil spillage with a bulk density of $1.78 \mathrm{~g} \mathrm{~cm}^{-3}$. At the second experiment in autumn, we applied a glass-fiber mesh covering the holes in the ingrowth-cores and lowered the bulk density to $1.44 \mathrm{~g} \mathrm{~cm}^{-3}$. The soil used for the ingrowth-cores was a sandy loam subsoil taken from below $0.5 \mathrm{~m}$ (Roskilde Stone \& Gravel Ltd.). Physical and chemical characteristics of subsoil medium are available in Table 1. After repacking is done, the ingrowth-cores were inserted into the access-tubes.

\section{Shoot sampling and measurement}

Two shoot samplings took place in both experiments at week 4 and 8 after the core-labelling. At week 4 young and old leaves were collected, separately, whereas the entire biomass was collected as a whole at week 8 .

Samples were collected directly above each of the three ingrowth-cores. Due to the insertion angle, each $0.55 \mathrm{~m}$ ingrowth-core had the corresponding length on the surface of $0.275 \mathrm{~m}$ (Fig. 4). Although the diameter of the ingrowth-core was $0.1 \mathrm{~m}$, we targeted at the width that corresponded to three crop rows (equivalent to $0.36 \mathrm{~m}$ ). Thus, the total area of sampling per opening was $0.275 \mathrm{~m} \times 0.360 \mathrm{~m}$ on the soil surface for both experiments. In the spring experiment, shoot samples were collected from three different spots. Firstly, shoots were sampled as described at the targeted areas directly above the labelled ingrowth-cores (core-spot; 0-0.36 m). In addition, the area around the core-spot was sampled (around-spot; 0.361-0.720 m), and as a control, shoot samples at least $5 \mathrm{~m}$ away from the core-spot were collected (remote-spot).

The collected samples were oven-dried at $85{ }^{\circ} \mathrm{C}$ for $48 \mathrm{~h}$, and ground for further analysis. Stable isotopic ratios of $\mathrm{N}\left({ }^{15} \mathrm{~N}\right)$ was measured at Stable Isotope Facility, UC Davis, using a ThermoScientific GasBench-Precon gas concentration system interfaced to a Thermo Scientific $^{\mathrm{TM}}$ DELTA V ${ }^{\mathrm{TM}}$ Plus isotope-ratio mass spectrometer (Bremen, Germany). Upon analysis of the nutrient analogues, the samples were microwave-digested in nitric acid (70\%). For the spring experiment, the sample digests 


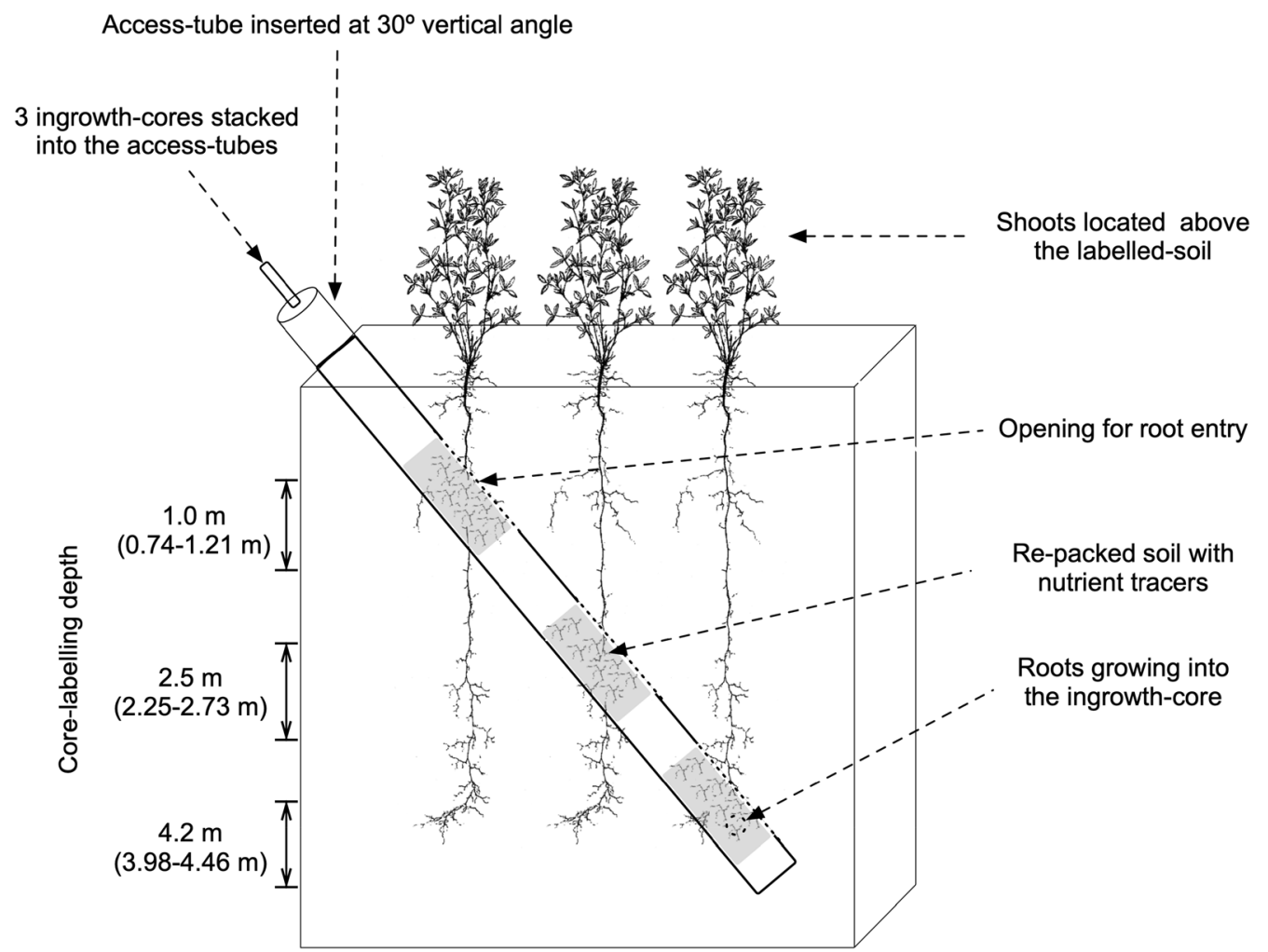

Fig. 3 A schematic diagram describing the concept of core-labelling technique (CLT); Figures of plants are from Kutschera et al. [31]

were analyzed by Inductively Coupled Plasma Mass Spectrometry (ICP-MS, Thermo Scientific iCAP-Q equipped with CCTED; collision cell technology with energy discrimination, Bremen, Germany). In the autumn experiment, the digests were analyzed using ICP Sector Field Mass Spectrometry (ICP-SFMS, ELEMENT XR, Thermo Scientific, Bremen, Germany) using a combination of internal standardization and external calibration.

In the autumn experiment, the tracer concentrations from the core-spots were subtracted to the tracer concentrations from the remote-spot to calculate the excess tracer concentrations (dTC).

\section{Root sampling and measurement}

The ingrowth-cores were retracted for root sampling after 8 weeks of core-labelling and the soil samples were stored in a cooling room $\left(5{ }^{\circ} \mathrm{C}\right)$ until the extraction. The entire volume of the soil re-packed into ingrowth-cores was taken out and visible roots were separated by root washing. The clean root samples were scanned on a flatbed scanner (Epson Perfection V700). The resulting root images (600 dots per inch; DPI) were analyzed with the 'WinRHIZO Pro' (Version 2016c, 32 Bit) software. Minimum surface area of the object was set for $2 \mathrm{~cm}^{2}$, and minimum length to width ratio of the root objects to 2 . Medium image smoothening was chosen for noise removal. Rootlength density (RLD; $\mathrm{cm} \mathrm{cm}^{-3}$ ), root diameter ( $\mathrm{mm}$ ) were obtained from the images. Root biomass (RBM; $\mathrm{mg} \mathrm{cm}{ }^{-3}$ ) was determined after drying the root samples for $48 \mathrm{~h}$ at $85{ }^{\circ} \mathrm{C}$ in the oven. Specific root length (SRL; $\mathrm{m} \mathrm{g}^{-1}$ ) was calculated based on RBM and RLD.

\section{Statistical analysis}

$\mathrm{R}$ version 3.4.1 $\mathrm{R}$ Core [44] was used for statistical analysis. The package lme4 [2] was used for linear mixedeffects model analysis [43]. For the root traits (RLD, RBM, root diameter, and SRL) the effects of core-labelling depth -1.0 and $2.5 \mathrm{~m}$ for the spring experiment and 1.0, 2.5 and $4.2 \mathrm{~m}$ for the autumn experiment, were tested. In the spring experiment, the effects of sampling distance (core-, around- and remote-spot) and corelabelling depth $(1.0$ and $2.5 \mathrm{~m})$ on the tracer concentrations in aboveground biomass were tested. In autumn experiment, the effects of sampling time (week 4 and 8) and core-labelling depth (1.0, 2.5 and $4.2 \mathrm{~m})$ on excess tracer concentrations (dTC) were tested. The effects 
Total plot width: $1.5 \mathrm{~m}$
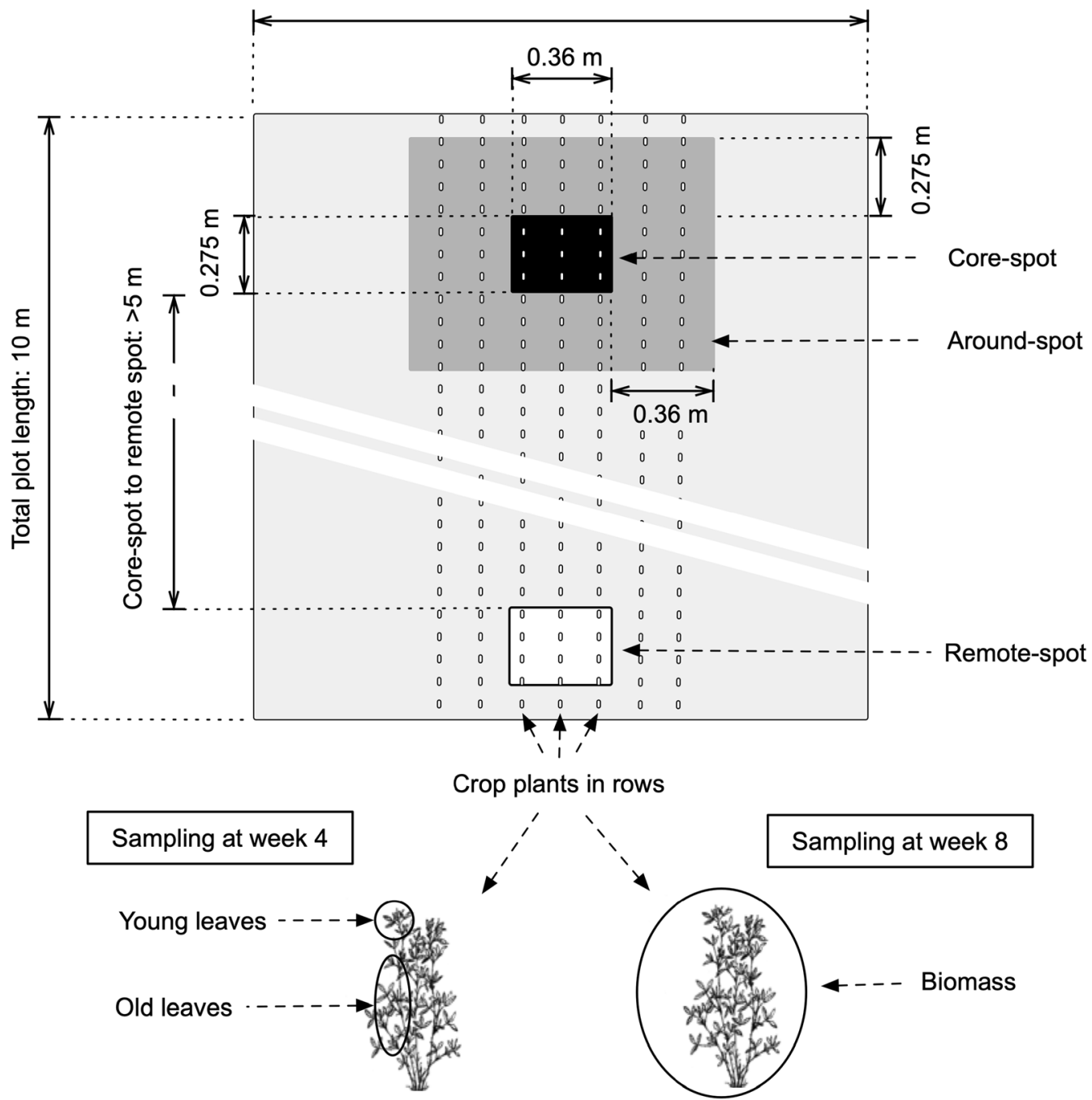

Fig. 4 A schematic diagram on shoot sampling strategies. In spring experiment: shoot samples for core-spot (black-shaded area) were collected within $0.275 \mathrm{~m} \times 0.360 \mathrm{~m}$ directly above the ingrowth-cores. Samples from around-spot (grey-shaded area) were collected around the core-spot (0.361-0.720 m). Shoot samples from remote-spot (white-shaded area) were collected $>5 \mathrm{~m}$ away from the core-spots. In both experiments: shoots were sampled twice (week 4 and week 8). At week 4, young and old leaves were collected separately, whereas the entire biomass was collected at week 8

of sampling part (young and old leaves) on the tracer concentrations measured after 4 weeks of core-labelling were tested in the spring and autumn experiments.

Main effects and interactions were tested for significance $(P \leq 0.05)$ based on the approximated degrees of freedom calculated by the package lmerTest [32]. Differences were considered significant at $\mathrm{P}<0.05$. Tukey test $\mathrm{P}$-values for pairwise comparisons were adjusted for multiplicity, by single step correction to control the family-wise error rate, using the multcomp package [19].

\section{Results}

Installation, cost and labour requirement for implementation of CLT

Depending on the soil and weather conditions, the soildrilling using a spiral auger and the insertion of accesstubes allowed the installation of 6-8 access-tubes per day with two labours. It indicates that one day was sufficient to install the required number of access-tubes for this study, which resulted in a cost of 7000 Euros (52,080 Danish Krone). Six days by one professional were required to produce 18 ingrowth-cores for the 
given study with a cost of 2830 Euros (21,120 Danish Krone).

Labelling of soil with the nutrient tracers and re-packing of the soil into 18 ingrowth-cores required less than a day with three labours. Insertion of the ingrowth-cores into the access-tubes required three labours, which was done in a day. We were able to finish the shoot sampling in a day with two labours. Extraction of ingrowth-cores required three labours and an electronic winch mounted on a tractor, and it required one day to complete.

\section{Alfalfa root growth into ingrowth-cores}

Roots of alfalfa grew into ingrowth-cores at all depths. The density-based traits such as RLD and RBM exhibited low amount and did not significantly differ between soil depths in either of the seasons (Fig. 5a, b, e and f). The variability in RLD in the spring experiment was high, from 0.003 to $0.082 \mathrm{~cm} \mathrm{~cm}^{-3}$ at $1.0 \mathrm{~m}$ depth. In spring, the root diameter decreased significantly with depth, which led to the significant effect of depth on SRL. No differences in root diameter and SLR between the depth was found in the autumn (Fig. $5 \mathrm{~g}$ and $\mathrm{h}$ ).

\section{Effect of sampling spot on tracer concentrations}

Concentration of tracers at different sampling spot with varying distance (core-spot, around-spot and remotespot) and core-labelling depth $(1.0 \mathrm{~m}$ and $2.5 \mathrm{~m})$ is presented here based on the data from the spring experiment. According to mixed-effects model analysis, core-labelling depth significantly affected tracer concentrations of ${ }^{15} \mathrm{~N}$ (Fig. 6a) while Li, Cs, Se and $\mathrm{Rb}$ were unaffected (Fig. 6b-e). Tracer concentrations of ${ }^{15} \mathrm{~N}, \mathrm{Cs}$ and Li were significantly affected by sampling spot. Se and $\mathrm{Rb}$ concentrations were affected by neither factor (Fig. 6d, e, i and j).

Multiple comparisons on tracer concentrations between the sampling spots were carried out. Tracer concentrations of ${ }^{15} \mathrm{~N}, \mathrm{Li}$ and Cs (Fig. $6 \mathrm{f}-\mathrm{h}$ ) were significantly higher at the core-spot compared to the remote-spot across the core-labelling depths, meanwhile the around-spot exhibited moderate differences. Se and $\mathrm{Rb}$ concentrations revealed decreases from the crop-spot to remote-spot, however, the differences were not significant (Fig. 6i and j).

\section{Effect of sampling time on excess tracer concentrations (dTC)}

In the autumn experiment, excess tracer concentrations (dTC) at three core-labelling depths (1.0, 2.5 and $4.2 \mathrm{~m})$ at two sampling times (week 4 and week 8) were analyzed. Regardless of core-labelling depth the dTC of ${ }^{15} \mathrm{~N}$ and $\mathrm{Li}$ was significantly affected by the core-labelling depth, in which, $1.0 \mathrm{~m}$ depth revealed significantly higher dTC (Fig. 7a and b). The difference between 2.5 and $4.2 \mathrm{~m}$ was insignificant. Cs dTC also revealed similar decrease along the depth, but the difference was not significant (Fig. 7c). Se dTC and Rb dTC were not affected by corelabelling depth (Fig. 7c, d and e). Cs dTC was significantly higher at week 8 compared with week 4 (Fig. 7h). Although ${ }^{15} \mathrm{~N}$, Li and Rb (Fig. 7f, g and j) showed similar
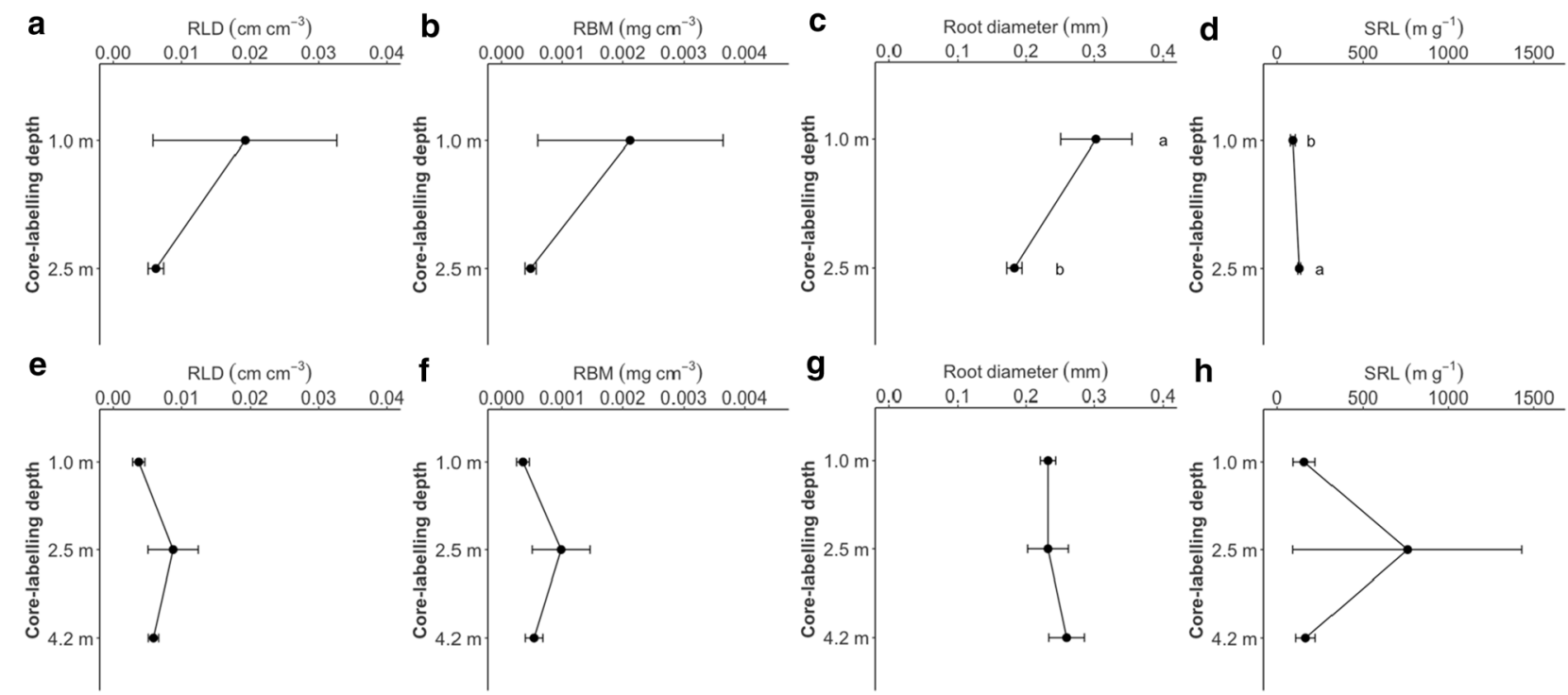

Fig. 5 Root-length density $\left(\mathrm{RLD} ; \mathrm{cm} \mathrm{cm}^{-3}\right.$ ), root biomass (RBM; $\mathrm{mg} \mathrm{cm}^{-3}$ ), root diameter $(\mathrm{mm})$ and specific root-length (SRL; $\left.\mathrm{g} \mathrm{m}^{-1}\right)$ of alfalfa affected by core-labelling depth measured in the spring $(\mathbf{a}-\mathbf{d})$ and autumn experiment $(\mathbf{e}-\mathbf{h})$. Small letters indicate significant differences between the treatments (Tukey HSD; $P \leq 0.05$ ). Means and one SE are shown 

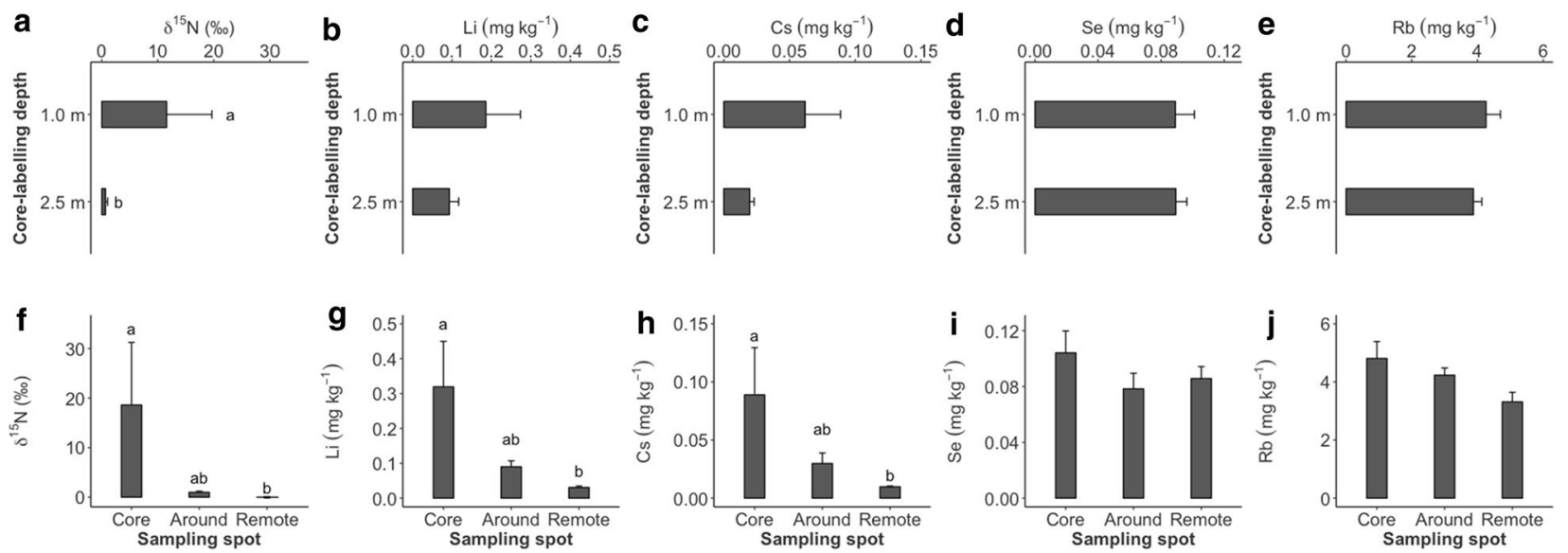

Fig. 6 Tracer concentration of ${ }^{15} \mathrm{~N}$, Li, Cs, Se and Rb in alfalfa shoot biomass affected by core-labelling depth (1.0 and $2.5 \mathrm{~m}$; a-e) sampling distance (core-, around- and remote-spot; $\mathbf{f}-\mathbf{j}$ ) in the spring experiment. Roman letters indicate significant differences between the treatments (HSD Tukey;

$P \leq 0.05)$. Means and one SE are shown

increase in $\mathrm{dTC}$ over the sampling time, the difference was not significant. $\mathrm{Rb}$ revealed a mild decrease in $\mathrm{dTC}$ over the sampling time, but the effects were insignificant.

\section{Effects of sampling part on tracer concentration}

In both experiments, shoot samples were separately collected from young and old leaves to compare the tracer concentrations between the sampling parts. As shown in Fig. 8 , the anionic tracers, i.e., ${ }^{15} \mathrm{~N}$ and Se, revealed significant differences in tracer concentrations between the sampling parts-Se in both experiments (Fig. 8d and i) and ${ }^{15} \mathrm{~N}$ in spring experiment (Fig. 8f). No other tracers exhibited the effects of sampling part (see Fig. 8b, c, e, g, h and j).

\section{Root density vs. tracer concentration}

We have found low values for both tracer concentrations and root density. Nevertheless, the relationships between RLD and tracers were significant $(P \leq 0.05) . \mathrm{R}^{2}$ values between RLDs and ${ }^{15} \mathrm{~N}, \mathrm{Li}, \mathrm{Cs}$, Se and $\mathrm{Rb}$ were 0.840 , $0.738,0.756,0.213$ and 0.630 , respectively (Fig. 9a-e). However, only few data points with high $\mathrm{x}$ and $\mathrm{y}$ values have driven the linear relationship.

\section{Discussion}

Using CLT, root activity was detected in the aboveground biomass above the core-labelled spot and the effects of core-labelling were also moderately shown up to $0.72 \mathrm{~m}$ of distance horizontally. Maximum root activity was shown earlier for the mobile anionic tracers compared to
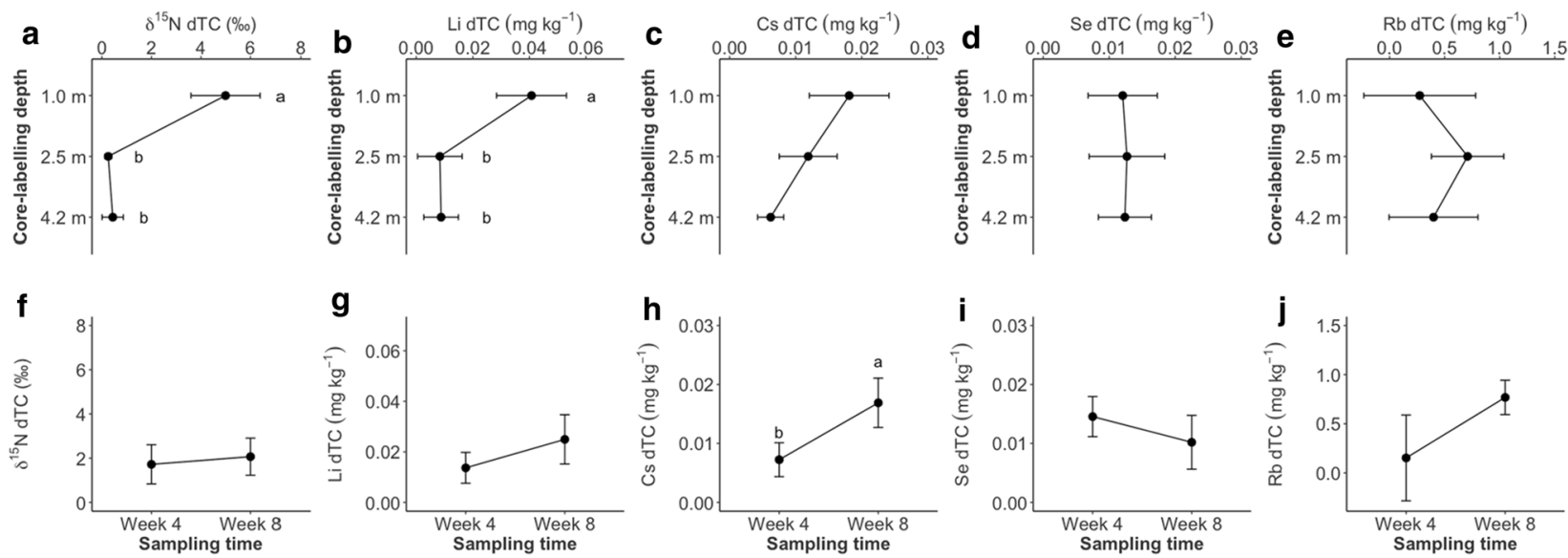

Fig. 7 Excess tracer concentrations (dTC) of ${ }^{15} \mathrm{~N}, \mathrm{Li}$, CS, Se and Rb from alfalfa shoot biomass affected by core-labelling depth (1.0, 2.5, 4.2 m; a-e) and sampling time (Week 4 and $8 ; \mathbf{f}-\mathbf{j}$ ) in the autumn experiment. Roman letters indicate significant differences between the treatments (HSD Tukey; $P \leq 0.05)$. Means and one SE are shown 

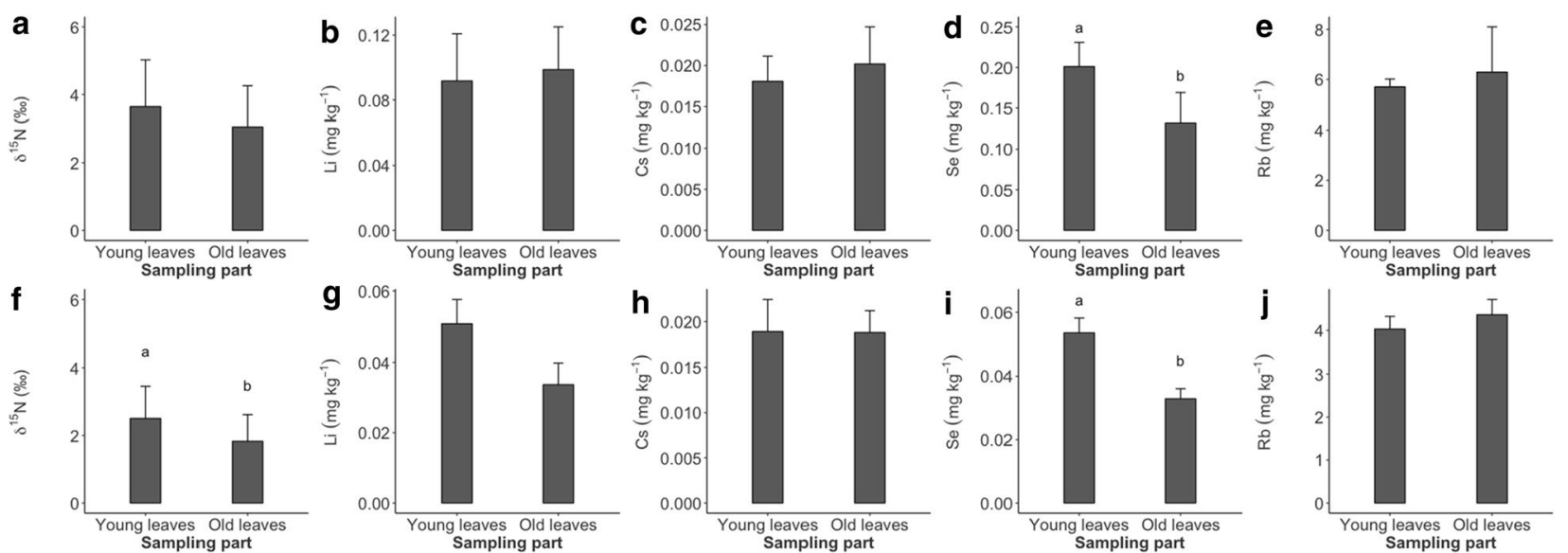

Fig. 8 Tracer concentration of ${ }^{15} \mathrm{~N}, \mathrm{Li}, \mathrm{Cs}$, Se and Rb in alfalfa shoot biomass affected by sampling part (young and old leaves) collected 4 weeks after the core-labelling in spring (a-e) and autumn experiment $(\mathbf{f}-\mathbf{j})$. Roman letters indicate significant differences between the sampling part (HSD Tukey; $P \leq 0.05)$, respectively. Statistical analysis was done with log-transformed variables. Means and one SE are shown

the less mobile cationic tracers. The relationship between rooting density and tracer uptake was positively correlated but considering the data distribution, it was rather inconclusive.

\section{Deep root growth into the ingrowth-cores}

As hypothesized (i), CLT, with its deep access-tubes and ingrowth-core installation, was capable of capturing deep root growth below $2 \mathrm{~m}$ depth. To our knowledge, this study illustrates the deepest application of an ingrowthcore technique, which, has commonly been used to a maximum of $0.5 \mathrm{~m}$ soil depth $[5,50]$. We found alfalfa root growth and activity at $4.2 \mathrm{~m}$ depth in autumn, which exceeds the deepest observation on alfalfa roots, so far, done by Weaver [58] at $3.7 \mathrm{~m}$ after 6-years cultivation of the species. In a Haplic Luvisol, perennial crops, such as alfalfa, chicory and tall fescue were found to have deep roots when observed to $2 \mathrm{~m}$ of soil depth [15, 24]. When grown as mixture with Festuca pratensis and Phleum pratense, alfalfa resulted in $1.5 \mathrm{~m}$ of maximum rooting depth [48]. In extreme cases soil water depletion has shown root activity of alfalfa deep roots up to $10 \mathrm{~m}$ of soil depth [10,34].

The deep-rooting of alfalfa in our study site must be attributed to its taproot system with a high penetration capacity [38]. The species is also known to create soil biopores [15]. The increase in biopore density formed by the penetration of large-sized taproots [23,39] might be responsible for establishment of deep roots. Another reason for deep rooting might be the less frequent mowing done at the study site (max. 3 cuts per season) which might have enhanced the rapid root growth [58]. Finally, the deep roots found could also be a result of methodological issues. Inserting tubes into the soil always poses the risk of disturbance e.g. leaving gaps between the tube and the soil facilitating root growth along the tube.

In contrast to the high rooting depth, we have found lower rooting density of alfalfa than expected. According to our observation, the ground water level at the study site was above $2.5 \mathrm{~m}$ depth during the incubation period, which might have affected the increase in rooting density. The frequency of sampling, in general, is perceived as $2-4$ weeks of time to ensure minimum root mortality of the ingrown fine roots $[6,50]$. In our study, we doubled the time, to allow time for tracer uptake after roots had grown into the ingrowth-cores. Therefore, it is hard to conclude if the sampled roots after 60 days were at the peak in terms of density. Moreover, as indicated in Table 1, we have used same soil batch for re-packing regardless of the depth-levels for ingrowth-core installation. As a result, there were differences in soil texture between bulk soil and the re-packed soil, especially at depth $(>3.0 \mathrm{~m})$, which might have retarded root growth into the ingrowth-cores due to the discontinuity in soil properties [4].

The surprising result that there were no significant differences in RLD between the three depths is expected to be a result of the high data variability, which might have been caused by heterogeneous root distribution in the deep soil layers [22] and the aforementioned limitation exerted by installation disturbance.

\section{Horizontal and vertical variation in root activity}

Our hypothesis (ii) was only partially met. We have identified the labelled area using the CLT as intended, but the range of labelling area was larger than we assumed. We have found a tendency that tracer concentration to be elevated at the around-spot. Considering the 

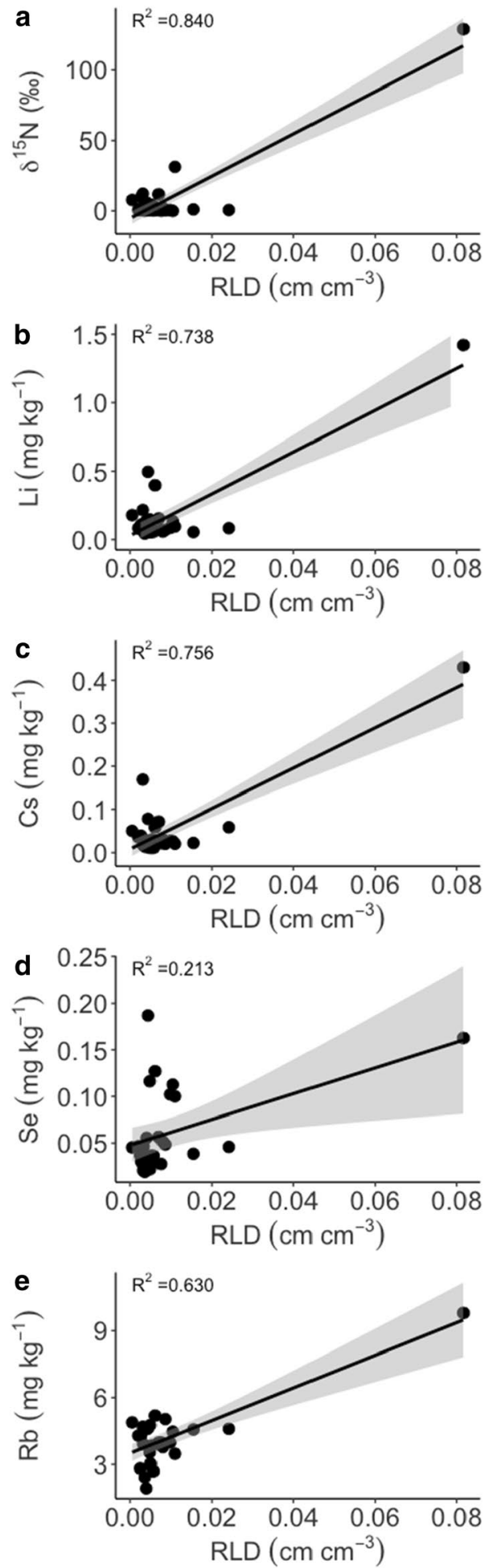

Fig. 9 Linear regression between root-length density (RLD; $\left.\mathrm{cm} \mathrm{cm}^{-3}\right)$ and nutrient tracers $\left({ }^{15} \mathrm{~N}, \mathrm{Li}, \mathrm{Cs}\right.$, Se and Rb). The shaded area represents one SE containment-capacity of CLT the uptake of tracers at around-spot should be interpreted as acquisition by the extended root system of the neighbor plants. This is also in agreement with previous studies. For example, when Li was applied as a tracer into $50 \mathrm{~cm}$ of soil depth at $327 \mathrm{ppm}(2 \mathrm{~g}$ of $\mathrm{LiCl}$ in $1000 \mathrm{~g}$ of soil), the adjacent maize plants up to $1 \mathrm{~m}$ distance were able to access the tracer [47]. However, it is uncertain to which extent the horizontal root proliferation happens when the deep roots are exposed to different conditions, such as soil compaction. One of the disadvantages of the generic injection techniques is its susceptibility for horizontal and vertical movement of the tracer solution after the injection, especially, due to high rainfall. In Hoekstra et al. [17], it was found that high rainfall (78 $\mathrm{mm}$ at the study site) during the incubation period caused increased concentration of the tracers ( $\mathrm{Cs}, \mathrm{Rb}$ and $\mathrm{Sr}$ ) below the injection depth. Based on our observation in the spring, such leakage of tracers from the ingrowth-cores did not happen or happened to a minimum extent.

In the spring experiment, root activity did not differ significantly between the soil depths. Nevertheless, root activity tended to be higher at the upper soil layers as the rooting density in upper layers tended to be higher, especially in spring. Despite the different depth-scale applied compared to the current study, Hoekstra et al. [17] found that the depth-wise difference in plant excess tracer concentration (dTC) and recovery rates of Cs between 0.05 and $0.2 \mathrm{~m}$ was more than 5 -folds when tested on a grass mixture. This is close to our findings in the spring experiment. The tracer concentration fell by a factor of 4.5 when the ingrowth-core depth was increased from 1.0 to $2.5 \mathrm{~m}$ in our experiment. Similarly, using $\mathrm{Sr}, \mathrm{Rb}$ and $\mathrm{Li}$, injection of tracer solutions at $0.05 \mathrm{~m}$ showed significantly higher root activity of seven grassland-species compared with injections at 0.15 and $0.25 \mathrm{~m}$ [11].

\section{Temporal variation in root activity}

The significant increases in excess tracer concentration (dTC) of Cs over the sampling time (from week 4 to 8) partially confirms our hypothesis (iii) stating that tracer concentration after longer incubation time is higher compared to shorter time. However, the time of sampling did not alter ${ }^{15} \mathrm{~N}$ and Se dTC. Considering the concentration differences between the young and old leaves, it is clear that the anionic tracers, i.e., ${ }^{15} \mathrm{~N}$ and $\mathrm{Se}$, seem to be taken up by deep roots within 4 weeks of incubation, whereas the cationic tracers required longer period time. 
In autumn experiment, regardless of sampling time, dTC of ${ }^{15} \mathrm{~N}, \mathrm{Li}, \mathrm{Cs}$ and Se revealed positive values indicating the tracer was taken up from week 4 or even earlier. However, tracer accumulation was not concentrated in younger leaves at that time for $\mathrm{Li}$ and Cs. This might be attributed to the accumulation pathways of the cations. Especially, Li is known to be firstly accumulated in the roots, then translocated to the old leaves and does not escape the location owing to the incapacity for phloem transport [25]. Overall, it can be suggested that the optimum period of incubation for ${ }^{15} \mathrm{~N}$ and $\mathrm{Se}$ is within 4 weeks, while the other tracers need longer time for optimal uptake and measurement. Therefore, we suggest that the optimum period for incubation in CLT should differ based on the tracers used.

Based on the data on the positive dTC values in autumn experiment (except for $\mathrm{Rb}$ at $1.0 \mathrm{~m}$ ), we assume that the tracer uptake happened up to $4.2 \mathrm{~m}$ of soil depth. However, we are also cautious to conclude on the uptake at depths, especially for Se and Rb. Firstly, no distinctive differences in dTC Se and dTC Rb between the soil depth may imply that the magnitude of tracer uptake was at very minimum level. Moreover, although we observed no indication of sharing ingrowth-cores between the plants at different depth-levels, at ground level the plants were separated by less than $1 \mathrm{~m}$ horizontally, which might have allowed a sharing of ingrowth-cores between plant from different depth-treatments, i.e. plants above ingrowth-cores inserted at $4.2 \mathrm{~m}$ were able to reach the ingrowth-cored inserted at $2.5 \mathrm{~m}$. Moreover, the overall concentrations of $\mathrm{Se}$ and $\mathrm{Rb}$ at the labelled area was low. Therefore, it is possible that even the small amount of $\mathrm{Se}$ and $\mathrm{Rb}$ snatched from upper-soil layers (e.g. from 2.5 m-labelled ingrowth-core) might have been substantial to indicate the significant effects of labelling.

\section{Root density vs. tracer uptake}

Our hypothesis (iv) on root density vs. tracer uptake was not confirmed by our CLT results. Despite the statistical indication by the linear regression, the relationship between root density and tracer uptake does not seem to be straight forward. The observed relationship was driven by one observation combining high root density with high uptake of all five tracers. First of all, we aimed to detect root activity at depth-levels where a low root growth was expected and shown. In addition, we did not substantially increase the enrichment levels of the nutrient tracers compared to other studies done on highly active root zones [18]. The reason was to avoid to affect root growth and activity of the target plants due to high concentrations of the applied chemicals [29], e.g. Toxicity in plants [49]. As a result, we had to work with a low labelling level close to the background levels and thereby a low increase in tracer concentration, which might have affected the relationship between the root density and shoot tracer concentration.

Hoekstra et al. [17] found that increasing injection density from 36 to 144 injections $\mathrm{m}^{-2}$ can reduce variability of tracer concentrations. It is difficult to compare this to the injection density of our approach. Yet considering the sampling area created per ingrowth-core $\left(0.099 \mathrm{~m}^{2}\right)$, it is approximately 10 injection points per $\mathrm{m}^{-2}$, which is substantially lower than previous studies (e.g. $>190$ injections per $\left.\mathrm{m}^{2}[21,40]\right)$, hence the risk for high variation in tracer concentration. One question remaining is, if the detected rooting density inside the ingrowth-cores would have been enough to draw the large proportion of tracer applied. In general, RLD higher than $0.1 \mathrm{~cm} \mathrm{~cm}^{-3}$ is a pre-requisite for a sufficient soil water extraction [20], which might be why the higher RLD values drove the linear relationship strongly in our study.

\section{Potential and improvement of the CLT method}

Our study shows the potential of the core-labelling technique (CLT) for studying deep nutrient uptake under field conditions, using either nutrient tracers $\left({ }^{15} \mathrm{~N}\right)$ or nutrient analogue tracers. Once produced and installed, the access-tubes and ingrowth-cores can be used for a long-term period, which can substantially reduce the workload and cost for research afterwards.

Despite the promising results, we have also identified some drawbacks of the approach. First of all, we have observed that the soil at the opening areas of access-tubes occasionally collapsed and left a dent, which potentially reduced bulk soil to re-packed soil contact. This might explain the large variation in root growth. Therefore, the design of the openings in the access-tubes may be adjusted to decrease the risk of soil-collapse while still allowing roots to grow across from the bulk soil to the ingrowth-core soil.

Moreover, due to the steep insertion angle the accesstube openings only left a short distance between the core-spots on the soil surface. This means that we cannot exclude the possibility of horizontal root growth and uptake from the shallower layers of plants supposedly taking tracers up from the deeper soil layers. However, as roots were found in all ingrowth-cores we expect the uptake to originate from there. The possible effect of horizontal growth could in future studies be determined by adding different tracers at the different depths and not using it for multiple tracer studies. Alternatively, a less steep insertion angle would separate the aboveground core-spots more but would require much longer access-tubes leading to increased potential of disturbance and impracticality upon insertion and extraction of the ingrowth-cores.

Except for ${ }^{15} \mathrm{~N}$, one question which remain is the effect of background concentration of the elements used 
as tracers on the results. In general, it is recommended to have information on their level of availability in the soil, before deciding the amount of label to apply to the ingrowth-core soil.

\section{Conclusions}

Our results suggest that CLT can be used to detect root activity of deep roots in arable fields. The approach combines deep-drilled permanent access-tubes installed at an angle, and portable ingrowth-cores used for placing labelled soil at different soil depths. Using CLT, researchers can locate the labelled spots underneath and be used to study spatial and temporal variation in root activity. The method has good potential for answering both basic and applied research questions about roots and their activity in deep soil layers. Further studies involving more realistic root-soil interface for determining deep root activity are required confirm the contribution deep roots to crop nutrient dynamics.

\section{Acknowledgements}

We are very grateful to Alan Hansen for co-designing and building the accesstubes and ingrowth-cores. Special thanks to Prof. Scott Young and his team at the University of Nottingham for processing our samples for ICP analysis. Paolo Mucci has provided a great assistance realizing the given method for both experiments. We thank Camilla Ruø Rasmussen for pre-reviewing our paper. We would like to thank the research technicians, especially, Jason Allen Teem, for his effortless support.

\section{Authors' contributions}

EH designed the access-tubes and ingrowth-cores, conducted the experiments and wrote the manuscript, while the co-authors proposed the core ideas and plan for the research. They have also participated in writing and proof-reading the manuscript. All authors read and approved the final manuscript.

\section{Funding}

We thank the Villum Foundation (DeepFrontier) for provision of funding for this study.

\section{Availability of data and materials}

The data will be stored on an online self-repository.

\section{Ethics approval and consent to participate}

Not applicable.

\section{Consent for publication}

All the authors have agreed on publication of this study.

\section{Competing interests}

Not applicable.

Received: 2 January 2020 Accepted: 26 May 2020

Published: 10 June 2020

\section{References}

1. Andersen SN, Dresbø\|l DB, Thorup-Kristensen K. Root interactions between intercropped legumes and non-legumes - a competition study of red clover and red beet at different nitrogen levels. Plant Soil. 2014;378:59-72. https://doi.org/10.1007/s11104-013-2014-4.
2. Bates D, Maechler M, Bolker B. 2013. Ime4: Linear mixed-effects models using $S 4$ classes, R package.

3. Böhm W. In situ estimation of root length at natural soil profiles. J Agric Sci. 1976;87:365.

4. Buol SW, Hole FD, McCracken RJ. Soil genesis and classification. lowa: lowa State University Press; 1989.

5. Chen S, Lin S, Reinsch T, Loges R, Hasler M, Taube F. Comparison of ingrowth core and sequential soil core methods for estimating belowground net primary production in grass-clover swards. Grass Forage Sci. 2016;71:515-28. https://doi.org/10.1111/gfs.12214.

6. Chen SM, Loges R, Biegemann T, Taube F. A study of ingrowth-core sampling frequency in a managed European grassland. Grassland-a European resource? EGF, Lublin, Poland. 2012;17:598-600

7. Collander R. Selective absorption of cations by higher plants. Plant Physiol. 1941;16:691-720. https://doi.org/10.1104/pp.16.4.691.

8. Da Silva EV, Bouillet JP, De Moraes Gonçalves JL, Junior CHA, Trivelin PCO, Hinsinger P, Jourdan C, Nouvellon Y, Stape JL, Laclau JP. Functional specialization of Eucalyptus fine roots: contrasting potential uptake rates for nitrogen, potassium and calcium tracers at varying soil depths. Funct Ecol. 2011;25:996-1006. https://doi.org/10.1111/j.1365-2435.2011. 01867.x.

9. do Rosário G, Oliveira M, van Noordwijk M, Gaze SR, Brouwer G, Bona S, Mosca G, Hairiah K. Auger sampling, ingrowth cores and pinboard methods. Root Methods. 2000. https://doi.org/10.1007/978-3-662-04188-8_6.

10. Fan J-W, Du Y-L, Wang B-R, Turner NC, Wang T, Abbott LK, Stefanova K, Siddique KHM, Li F-M. Forage yield, soil water depletion, shoot nitrogen and phosphorus uptake and concentration, of young and old stands of alfalfa in response to nitrogen and phosphorus fertilisation in a semiarid environment. Field Crops Res. 2016;198:247-57. https://doi.org/10.1016/j. fcr.2016.08.014

11. Fitter AH. Spatial and temporal patterns of root activity in a species-rich alluvial grassland. Oecologia. 1986;69:594-9.

12. Foyjunnessa F, McNeill A, Doolette A, Mason S, McLaughlin MJ. In situ 33P-labelling of canola and lupin to estimate total phosphorus accumulation in the root system. Plant Soil. 2014;382:291-9.

13. Fry B. Using stable isotope tracers. Stable Isotope Ecology. Baton Rouge: Springer; 2007. p. 40-67.

14. Gahoonia TS, Nielsen NE. 1998. Root activity and acquisition of soil phosphorus and potassium, In: Box, JE (Ed.), Root demographics and their efficiencies in sustainable agriculture, grasslands and forest ecosystems: Proceedings of the 5th Symposium of the International Society of Root Research, Held 14-18 July 1996 at Madren Conference Center, Clemson University, C. Springer Netherlands, Dordrecht, p. 331-44. https://doi.org/ 10.1007/978-94-011-5270-9_27.

15. Han E, Kautz T, Perkons U, Lüsebrink M, Pude R, Köpke U. Quantification of soil biopore density after perennial fodder cropping. Plant Soil. 2015;394:73-85. https://doi.org/10.1007/s11104-015-2488-3.

16. Himmelbauer M, LoiskandI W, Rousseva S. Spatial root distribution and water uptake of maize grown on field with subsoil compaction. J Hydrol Hydromech. 2010;58:163-74. https://doi.org/10.2478/v10098-010-0015-z.

17. Hoekstra NJ, Finn JA, Buchmann N, Gockele A, Landert L, Prill N, SchererLorenzen M, Lüscher A. Methodological tests of the use of trace elements as tracers to assess root activity. Plant Soil. 2014;380:265-83. https://doi. org/10.1007/s11104-014-2048-2.

18. Hoekstra NJ, Suter M, Finn JA, Husse S, Luescher A. Do belowground vertical niche differences between deep-and shallow-rooted species enhance resource uptake and drought resistance in grassland mixtures? Plant Soil. 2015;394:21-34.

19. Hothorn T, Bretz F, Westfall P, Heiberger RM, 2019. Package "multcomp.".

20. Kage $H$, Ehlers W. Does transport of water to roots limit water uptake of field crops? Z Pflanzenernahr Bodenk. 1996;159:583-90. https://doi.org/ 10.1002/jpln.1996.3581590609.

21. Kahmen A, Renker C, Unsicker SB, Buchmann N. Niche complementarity for nitrogen: an explanation for the biodiversity and ecosystem functioning relationship. Ecology. 2006. https://doi.org/10.1890/0012-9658(2006) 87\%5b1244:ncfnae\%5d2.0.co;2.

22. Kautz T, Amelung W, Ewert F, Gaiser T, Horn R, Jahn R, Javaux M, Kemna A, Kuzyakov Y, Munch JC, Pätzold S, Peth S, Scherer HW, Schloter M, Schneider H, Vanderborght J, Vetterlein D, Walter A, Wiesenberg GLBB, Köpke U. Nutrient acquisition from arable subsoils in temperate climates: a review. 
Soil Biol Biochem. 2013;57:1003-22. https://doi.org/10.1016/j.soilbio.2012. 09.014.

23. Kautz T, Lüsebrink M, Pätzold S, Vetterlein D, Pude R, Athmann M, Küpper PM, Perkons U, Köpke U. Contribution of anecic earthworms to biopore formation during cultivation of perennial ley crops. Pedobiologia. 2014;57:47-52. https://doi.org/10.1016/j.pedobi.2013.09.008.

24. Kautz T, Stumm C, Kösters R, Köpke U. Effects of perennial fodder crops on soil structure in agricultural headlands. J Plant Nutr Soil Sci. 2010;173:490501. https://doi.org/10.1002/jpln.200900216.

25. Kent NL. Absorption, translocation and ultimate fate of lithium in the wheat plant. New Phytol. 1941;40:291-8. https://doi.org/10.1111/j.14698137.1941.tb07051.x.

26. Keyes MR. Ecosystyem development in Abies amabilis stands of the Washington cascades: root growth and its role in net primary production. Washington: University of Washington; 1982.

27. Kirkegaard JA, Lilley JM, Howe GN, Graham JM. Impact of subsoil water use on wheat yield. Aust J Agric Res. 2007;58:303-15. https://doi.org/10. 1071/AR06285.

28. Klodd AE, Eissenstat DM, Wolf TK, Centinari M. Coping with cover crop competition in mature grapevines. Plant Soil. 2016;400:391-402. https:// doi.org/10.1007/s11104-015-2748-2.

29. Kolbert Z, Lehotai N, Molnár Á, Feigl G. "The roots” of selenium toxicity: a new concept. Plant Signal Behav. 2016;11:e1241935. https://doi.org/10. 1080/15592324.2016.1241935.

30. Kristensen HL, Thorup-Kristensen K. Root depth and nitrogen uptake from deep soil layers in organic vegetable production - a preliminary study. Acta Hort. 2002;571:203-8. https://doi.org/10.17660/ActaHortic 2002.571.24.

31. Kutschera, L., Lichtenegger, E., Sobotik, M., 2009. Wurzelatlas der Kulturpflanzen gemäßigter Gebiete mit Arten des Feldgemüsebaues. DLG-Verlag.

32. Kuznetsova A, Brockhoff PB, Christensen RHB, 2015. Package "ImerTest."R Package Version.

33. Lehmann J, Muraoka T. Tracer methods to assess nutrient uptake distribution in multistrata agroforestry systems. Agrofor Syst. 2001;53:133-40. https://doi.org/10.1023/A:1013368302450.

34. Li Y, Huang M. Pasture yield and soil water depletion of continuous growing alfalfa in the Loess Plateau of China. Agr Ecosyst Environ. 2008. https://doi.org/10.1016/j.agee.2007.08.007.

35. Lynch JP, Wojciechowski T. Opportunities and challenges in the subsoil: pathways to deeper rooted crops. J Exp Bot. 2015;66:2199-210.

36. Malcolm BJ, Cameron KC, Di HJ, Edwards GR, Moir UL. The effect of four different pasture species compositions on nitrate leaching losses under high N loading. Soil Use Manag. 2014;30:58-68. https://doi.org/10.1111/ sum.12101.

37. Martin MPLD, Snaydon RW, Drennan DSH. Lithium as a non-radioactive tracer for roots of intercropped species. Plant Soil. 1982;64:203-8. https:// doi.org/10.1007/BF02184251.

38. Materechera SA, Alston AM, Kirby JM, Dexter AR. Influence of root diameter on the penetration of seminal roots into a compacted subsoil. Plant Soil. 1992;144:297-303. https://doi.org/10.1007/BF00012888.

39. McCallum MH, Kirkegaard JA, Green TW, Cresswell HP, Davies SL, Angus JF, Peoples MB. Improved subsoil macroporosity following perennial pastures. Aust J Exp Agric. 2004;44:299-307. https://doi.org/10.1071/EA030 76.

40. McKane RB, Johnson LC, Shaver GR, Nadelhoffer KJ, Rastetter EB, Fry B, Giblin AE, Kielland K, Kwlatkowski BL, Laundre JA, Murray G. Resourcebased niches provide a basis for plant species diversity and dominance in arctic tundra. Nature. 2002. https://doi.org/10.1038/415068a.

41. McLaren TI, McBeath TM, Simpson RJ, Richardson AE, Stefanski A, Guppy CN, Smernik RJ, Rivers C, Johnston C, McLaughlin MJ. Direct recovery of33P-labelled fertiliser phosphorus in subterranean clover (Trifolium subterraneum) pastures under field conditions-the role of agronomic management. Agr Ecosyst Environ. 2017;246:144-56. https://doi.org/10. 1016/j.agee.2017.05.029

42. Pearson JN, Jakobsen I. The relative contribution of hyphae and roots to phosphorus uptake by arbuscular mycorrhizal plants, measured by dual labelling with 32P and 33P. New Phytol. 1993;124:489-94. https://doi.org/ 10.1111/j.1469-8137.1993.tb03840.x.

43. Pinheiro J, Bates D. Mixed-effects models in S and S-PLUS, statistics and computing. New York: Springer; 2000. https://doi.org/10.1007/b98882.

44. R Core Team, 2019. R: A language and environment for statistical computing.

45. Rasmussen IS, Dresbø\|l DB, Thorup-Kristensen K. Winter wheat cultivars and nitrogen ( $\mathrm{N}$ ) fertilization-Effects on root growth, N uptake efficiency and $\mathrm{N}$ use efficiency. Eur J Agron. 2015;68:38-49. https://doi.org/10. 1016/j.eja.2015.04.003.

46. Rasmussen IS, Thorup-Kristensen K. Does earlier sowing of winter wheat improve root growth and N uptake? Field Crops Res. 2016;196:10-21. https://doi.org/10.1016/j.fcr.2016.05.009.

47. Sayre JD, Morris VH. The lithium method of measuring the extent of corn root systems. Plant Physiol. 1940;15:761-4. https://doi.org/10.1104/pp. 15.4.761.

48. Schoo B, Schroetter S, Kage H, Schittenhelm S. Root traits of cup plant, maize and alfalfa grass grown under different soil and soil moisture conditions. J Agron Crop Sci. 2017;203:345-59. https://doi.org/10.1111/ jac.12194.

49. Shahzad B, Tanveer M, Hassan W, Shah AN, Anjum SA, Cheema SA, Ali I. Lithium toxicity in plants: reasons, mechanisms and remediation possibilities—a review. Plant Physiol Biochem. 2016;107:104-15. https:// doi.org/10.1016/.jplaphy.2016.05.034.

50. Steingrobe B, Schmid H, Claassen N. The use of the ingrowth core method for measuring root production of arable crops-influence of soil conditions inside the ingrowth core on root growth. J Plant Nutr Soil Sci. 2000;163:617-22. https://doi.org/10.1002/1522-2624(200012)163:6\% 3c617:AID-JPLN617\%3e3.0.CO;2-0.

51. Su W, Liu B, Liu X, Li X, Ren T, Cong R, Lu J. Effect of depth of fertilizer banded-placement on growth, nutrient uptake and yield of oilseed rape (Brassica napus L.). Eur J Agron. 2015;62:38-45.

52. Terry N, Zayed AM, de Souza MP, Tarun AS. Selnium in higher plants. Annu Rev Plant Physiol Plant Mol Biol. 2000;51:401-32. https://doi.org/10.1146/ annurev.arplant.51.1.401.

53. Thorup-Kristensen K. Root growth and nitrogen uptake of carrot, early cabbage, onion and lettuce following a range of green manures. Soil Use Manag. 2006;22:29-38. https://doi.org/10.1111/j.1475-2743.2005.00012.x.

54. Vogt KA, Persson H. Root methods. In: Lassoie JP, Hinckley TM, editors. Techniques and approaches in forest tree ecophysiology. Boca Raton: CRC Press; 1991. p. 477-502.

55. Volkmar KM. Effects of biopores on the growth and N-uptake of wheat at three levels of soil moisture. Can J Soil Sci. 1996;76:453-8. https://doi.org/ 10.4141/cjss96-056.

56. Wasson AP, Nagel KA, Tracy S, Watt M. Beyond digging: noninvasive root and rhizosphere phenotyping. Trends Plant Sci. 2020;25:119-20. https:// doi.org/10.1016/j.tplants.2019.10.011.

57. Wasson AP, Rebetzke GJ, Kirkegaard JA, Christopher J, Richards RA, Watt M. Soil coring at multiple field environments can directly quantify variation in deep root traits to select wheat genotypes for breeding. J Exp Bot. 2014. https://doi.org/10.1093/jxb/eru250.

58. Weaver J. Root habits of alfalfa. Root development of field crops. New York: McGraw-Hiil; 1926

59. White PJ, Broadley MR. Mechanisms of caesium uptake by plants. New Phytol. 2000;147:241-56.

60. White RG, Kirkegaard JA. The distribution and abundance of wheat roots in a dense, structured subsoil-implications for water uptake. Plant Cell Environ. 2010;33:133-48. https://doi.org/10.1111/j.1365-3040.2009. 02059.x.

\section{Publisher's Note}

Springer Nature remains neutral with regard to jurisdictional claims in published maps and institutional affiliations. 